UDK: 811.163.42'38:821.163.42-31

Izvorni znanstveni članak

Primljen 28. IX. 2019.

IVONA BAKOVIĆ

Filozofski fakultet Sveučilišta u Mostaru

ivona.bakovic@ff.sum.ba

\title{
SINTAKTOSTILEMI U ROMANIMA HRVATSKE PROZE U TRAPERICAMA
}

\section{Sažetak}

$\mathrm{U}$ radu se analiziraju sintaktostilemi u trima romanima hrvatske proze u trapericama: Kratki izlet Antuna Šoljana, Kužiš, stari moj Zvonimira Majdaka i Bolja polovica hrabrosti Ivana Slamniga. Obuhvaćene su pojave i postupci na sintaktičkoj razini (dekomponirani predikat, elipsa, reticencija, nominativne rečenice, parcelacija, inverzija, ponavljanja i epiteti) u kojima nalazimo odstupanja od ustaljene rečenične strukture. Budući da je u prozi u trapericama riječ o stilizaciji usmenoga govora, postupcima poput elipse i reticencije postiže se dojam spontanosti i nepripremljenosti, dok, primjerice, ponavljanja, osim što pridonose neusiljenosti i opuštenosti, mogu otkrivati i emocionalna stanja protagonista.

Ključne riječi: proza u trapericama; ekspresivna sintaksa; sintaktostilem; stilske figure; rečenica

\section{Uvod}

Šezdesetih godina prošloga stoljeća u hrvatskoj se književnosti, kao opreka problemskomu intelektualizmu moderne proze, počinje oblikovati poseban prozni model - proza u trapericama (engl. jeans prose). ${ }^{1}$

Aleksandar Flaker prozu u trapericama definira kao „prozu u kojoj se pojavljuje mladi pripovjedač (bez obzira na to da li on nastupa u prvom ili trećem licu) koji izgrađuje svoj 
Karakterizira je središnji lik buntovnoga mladića, koji je najčešće i pripovjedač, gradskoga frajera i marginalca koji se ne uklapa u društvenu sredinu i malograđansku kulturu, nego očituje snažnu pripadnost manjoj društvenoj skupini - klapi. Glavni lik i njegova klapa svojim načinom života, svjetonazorima i idealima, pa i jezikom, osporavaju tradicionalne društvene i kulturne norme, afirmiraju svoju kulturu, svoj način odijevanja i svoj jezik.

U hrvatskoj književnosti zametke proze u trapericama nalazimo već u prvim romanima Antuna Šoljana (Izdajice, 1961.; Kratki izlet, 1965.), ali zlatno doba proze u trapericama sedamdesete su godine prošloga stoljeća kada nastaju romani Alojza Majetića (Čangi off gottoff, 1970.), Zvonimira Majdaka (Kužiš, stari moj, 1970.; Stari dečki, 1975.) i Ivana Slamniga (Bolja polovica hrabrosti, 1972.).

Pripovijedanje u prozi $u$ trapericama približava se pripovjedačevu usmenom spontanom govoru, a to se načelo ostvaruje stilizacijom, odnosno tako što se stilističkim sredstvima nastoji stvoriti iluzija usmenoga govora. ${ }^{2}$ Takav je govor spontan, nepripremljen, česte su stanke, prekidanja iskaza kao i ponavljanja dijelova iskaza. Cilj je ovoga rada na odabranim romanima prikazati stileme na sintaktičkoj razini (sintaktostileme) i njihovu funkcionalnostilsku i ekspresivnu obilježenost. ${ }^{3}$

Stilematičnost i stilogenost jezične jedinice rezultat su različitih transformacija nestilematične jedinice. ${ }^{4}$ Prema antičkim retoričarima četiri su postupka strukturno-semantičkoga oneobičavanja nestilematičnih jedinica na kojima se temelji tvorba stilematičnih jedinica (koje dobivaju narav stilskih figura), a to su: 1. imutatio (supstitucija, zamjena)

osebujni stil na temelju govorenog jezika gradske omladine i osporava tradicionalne i postojeće društvene i kulturne strukture". AleKSANDAR Flaker, Proza u trapericama, Sveučilišna naklada Liber, Zagreb, 1983., str. 36.

$2 \quad$ Usp. isto, str. 98.

3 Za potrebe ovoga istraživanja rabljene su pokrate: KI (Kratki izlet), KSM (Kužiš, stari moj) i BPH (Bolja polovica hrabrosti.

4 Usp. Bernisa PURIš, „Ekspresivna sintaksa u književnoumjetničkom tekstu (na primjeru Grozdanina kikota Hamze Hume)“, Post scriptum, Bihać, br. 1 (2010. - 2011.), str. 24. - 30.; Ivo Pranjković, „Stilske figure i gramatika“, Jezik književnosti i književni ideologemi: zbornik radova 35. seminara Zagrebačke slavističke škole, KREŠIMIR BAGIĆ (ur.), Zagrebačka slavistička škola, Zagreb, 2007., str. 21. - 25. 
- jedan se element zamjenjuje drugim; 2. adiectio (dodavanje, umnožavanje) - postojećemu se elementu dodaje drugi; 3. detractio (oduzimanje, izostavljanje) - jednoj se jedinici oduzme kakav element ili se izostavi dio neke cjeline i 4. transmutatio (premještanje, permutacija) jezični elementi zamjenjuju mjesta, tj. jedan se element nađe na mjestu drugoga. Međutim, sama transformacija strukture ne čini koji element stilogenim; tek njegova funkcija u određenome kontekstu omogućuje mu status jedinice koja nosi ekspresivnost.

Marina Katnić-Bakaršić kao primjere zanimljivih sintaktostilema navodi dekomponirane predikate, nominalizaciju te različite postupke ekspresivne sintakse: elipsu, parcelaciju, inverziju i slično. ${ }^{5}$ Budući da je u prozi u trapericama riječ o stilizaciji usmenoga govora, postupcima poput elipse i reticencije postiže se dojam spontanosti i nepripremljenosti, dok, primjerice, ponavljanja, osim što pridonose neusiljenosti i opuštenosti, mogu otkrivati i emocionalna stanja protagonista.

\section{Dekomponirani predikat i nominalizacija}

Dekomponirani predikat sastoji se od jedne glagolske kopule ili semikopulativnoga glagola i glagolske imenice u kosome padežu, npr. dati odgovor - odgovoriti. Jednostavni glagolski predikat u takvim je parovima stilski neutralan, sinonimičan dekomponiranomu i komutabilan $\mathrm{s}$ njim. „Primjeri sa dekomponiranim predikatom frekventniji su u zvaničnim i tzv. 'pisanim' stilovima, a njihova upotreba u razgovornom stilu obično pokazuje da govornik ne posjeduje dovoljnu stilističku kompetenciju, kompetenciju koja uključuje preključivanje sa jednog potkoda na drugi. “ ${ }^{\text {“ }}$ Preuzimajući dekomponirani predikat iz „Zvaničnih" stilova, govornici žele svojim iskazima dati težinu i ozbiljnost. Vrlo često je učinak suprotan jer dekomponirani predikat može biti „strano tijelo“ u razgovornome stilu i svakodnevnoj komunikaciji.

Dekomponirani je predikat jedna od pojava koja vodi nominalizaciji u jeziku, odnosno pojavljivanju nominalnih sredstava umjesto verbalnih.

Usp. Marina Katnić-BaKaršić, Stilistika, Ljiljan, Sarajevo, 2001., str. 257.

Isto, str. 258. 
Nominalizacija je karakteristična za pisane tekstove administrativnoga, publicističkoga i znanstvenoga funkcionalnog stila, zbog čega se ti stilovi smatraju nominalnim stilovima, za razliku od razgovornoga i književnoumjetničkoga koji se smatraju verbalnim. ${ }^{7}$ Evo nekoliko primjera:

Neki su čak poduzimali putovanja do nekih mjesta... (KI: 20)

Stalno se savjetuje i luplje po čelu da se treba uozbiljiti, i baš svakom ne reći sve što mu je na jeziku, ali drugačije dela $i$ što mu vrijedi što si daje najbolje savjete?! (KSM: 12); Kit se nastavio baviti čopavanjem mački. (KSM: 14); Sve je češće pogledom počašćivao mačke što su cugale u Čombrinoj sjeni i ozbiljno postavljao sebi pitanje šta bi se tu dalo izvesti. (KSM: 88); Nitko nije znao kaj dela, ali to vjerojatno zato jer je to pitanje postavljati u njegovoj klapi bilo zabranjeno. (KSM: 95); Ali gdje si onda ti, ni do kakvog rješenja ne možeš doći ako sve ide in kontinuo, a, ostalom, ako $i$ ne postoji kolektivno sjećanje, postoji mogućnost da se sve svede na jedan zajednički nazivnik onoga što je postojalo... (KSM: 108)

Premda se književnoumjetnički stil, kako je već rečeno, u načelu smatra verbalnim stilom, dekomponirani se predikat često javlja kao ekspresivno sredstvo.

\section{Postupci ekspresivne sintakse - sintaktičke figure}

\subsection{Elipsa}

Elipsa $^{8}$ podrazumijeva izostavljanje ili dokidanje dijelova iskaza, čime se narušava sintaktička norma, a izostavljeni dijelovi mogu se rekonstruirati zahvaljujući kontekstu. Ponekad je elipsa rezultat dokidanja zališnosti u iskazu, npr. A: Kamo ideš?; B: U crkvu., međutim takve se elipse ne mogu smatrati figurativnima, nego posljedicom jezične ekonomije. Izdvojili smo sljedeće primjere elipse koje imaju ekspresivnu vrijednost:

Kao da su vas s robije pustili. Pustite, ljudi. Poslije. Kasnije. Treba ići dalje. Hajdemo, molim vas lijepo. Hajde, kad vam kažem. Nije više daleko.

Usp. isto, str. 259.

8 Usp. Krešimir BAgIĆ, Rječnik stilskih figura, Školska knjiga, Zagreb, 2012., str. 93. 
Zaboravili ste: Gradina čeka. Zar ćete s ovima ovdje... Zbog ovih ovdje... Ljudi, idemo... (KI: 47)

Kamene kocke množe se pod našim nogama, pravilne, jednake, bezbrojne. I između kocaka - trava, Bože, kakva trava! (KI: 78)

Bilo je to kao neko sablasno novo rođenje na gluho tlo. Ništa. Ništa. Ništa. (KI: 112)

Unatoč svojoj glomaznosti, vrata se lagano i gotovo bez šuma otvoriše. Miris staroga drva, uski hodnik, drugi svijet. (BPH: 17)

A onda, trenutak svemirske jeze. (BPH: 61)

Razuman uzmak - bolja polovica hrabrosti. (BPH: 111)

\subsection{Reticencija}

Elipsi je srodna reticencija - figura nedovršenih rečenica, prekinutih iskaza, ali na način da se čitatelja potakne da pronađe/pogodi neizrečeno. Prema mišljenju Krešimira Bagića nedovršeni iskazi mogu značiti neuspješno traganje za pravim izrazom, mogu biti znak iznenađenja, prijetnje, aluzije ili oblik kojim se stvara napetosti: ${ }^{9}$

Svi su bili u ratu - rekao je Roko. - Ovako ili onako. Zar ovdje nije...?

Nije se ni sam usudio da dovrši. (KI: 81)

I ne sanjaju koliko će ih to koštati baš kao što je i mog frenda Glistu koštalo... (KSM: 28)

- Kako ti to... Samo onako. Bez pitanja. Tko ti je prišapnuo da ću ja platiti tvoju pijaču?! (KSM: 93)

Premda... Do bijesa i takvo kajanje! Ništa se tu ne da pomoći. Stvar je izvedena i šlus! (KSM: 122)

\subsection{Nominativne rečenice}

Nominativne rečenice često su u retorici smatrane podvrstom elipse, odnosno elipsom u širem smislu. Kod njih izostaje predikat, a njegovu predikativnost preuzima nominativna riječ ili sintagma. Zastupljene su $u$ različitim stilovima, a osobito je ekspresivna njihova pojava u poeziji.

$\overline{9} \quad$ Usp. isto, str. 271. 
Cijeli je izraz sažet, a nominalizirano predstavlja zbivanje ili stanje, stoga su često prisutne u opisnim dijelovima teksta:

Poslije, neko se vrijeme apsolutno ništa nije dogadalo. Mrtvilo! (KSM: 18)

\subsection{Parcelacija}

Parcelacija predstavlja realizaciju jedne rečenice u više tekstnih jedinica ili jednoga iskaza u nizu intonacijski izdvojenih segmenata međusobno odvojenih točkama. ${ }^{10}$ Pritom se izdvaja bazna komponenta, koja je gramatički i strukturno samostalna, i parcelat, koji je strukturno uvjetovan baznom komponentom. Uz jednu baznu komponentu može doći više parcelata, npr.:

Ništa nas više ne može zaustaviti, mislio sam. Nikakva zapreka, nikakva klopka. (KI: 73)

To ne znači da se vraćamo. Samo tražimo. Tražimo te... znakove. Ostatke. Spomenike. Prošlost. Trenutno tražimo freske. (KI: 82)

Previše je bilo kostiju u hodniku da bih nastavio. Previše urušenih mjesta; previše slijepih odvojaka. (KI: 88)

Bila je to velika biblioteka. Mnogo iluminiranih rukopisa, prijepisa, pergamena... i nisam je sačuvao. Od miševa. Od vlage. Od plijesni. Ali najviše od vremena. Sve je otišlo. (KI: 96)

I shvatio sam kako je besmisleno što ga optužujem za izdaju kad između nas nikada ništa nije postojalo, niti je moglo postojati. Nikakav zavjet, nikakav ugovor. (KI: 105)

Tako smo se nas dva stara borca rastali. Na vrijeme. (KSM: 79)

Kako sam to samo mogao učiniti?! Baš sam bludnik. Kreten. Svinja. Podlac. Majmun. Primitivac. Neandertalac. Četnik. Ustaša. Da, ja sam ustaša! (KSM: 113)

Došao je čas. Osjećam. Moj me pastir zove da mu položim račun. Što sam danas obrstio. Koga sam uvrijedio. Samo u tišini crkve naći ću svoj mir $i$ pribaviti san. Za noć otkupljenja. Od grijeha bluda. Obljube zvjerske. Idemo. Amen! (KSM: 132)

10 Usp. M. Katnić-BAKARŠıć, $n$. dj., str. 262. 
Unutra se nalazio kompletan Herder - izdanje sredinom prošloga stoljeća, ali izgledalo je nekako starije, Mikloušić, pa čaki Belostenec - to je već bilo nešto. Nešto molitvenika, jedna madžarska knjiga od koje sam uspio shvatiti samo godinu izdanja (1832), francusko-njemačka konverzacija $i z$ 1812, Schreinerova "Slawische Alterthumer" (s bilješkama olovkom) $i$, konačno, početnica izdana u Varaždinu 18oo! To je bio uspjeh! (BPH: 19)

S obzirom na to da parcelacija ponekad asocira na elipsu (zbog odsutnosti predikata u objema figurama), važno je istaknuti osnovne razlike među njima. Parcelati se, za razliku od elipsi, mogu učlaniti u prethodnu rečenicu, oni s baznom komponentom čine iskaznu realizaciju jedne rečenične strukture. S druge strane, eliptične su rečenice informacijski autonomne, a svaka je elipsa zasebna rečenica u odnosu na ostale koje je okružuju. ${ }^{11}$

\subsection{Inverzija}

Inverzija je promjena reda riječi u sintagmi i rečenici ili promjena redoslijeda glavne i zavisne surečenice. U stilističkoj literaturi ističe se da treba razlikovati gramatičku inverziju od stilističke. Bagić smatra da "gramatička inverzija pretpostavlja kontekstom uvjetovano odstupanje od ustaljene rečenične sheme subjekt - predikat - objekt te pojavu obavijesnog predikata ispred obavijesnog subjekta“, dok „stilistička inverzija pretpostavlja stilski obilježen red riječi, kojim govornik ili pisac naglašava pojedine riječi i njihova značenja, stvara učinak iščekivanja, ritmizira i estetizira iskaz" ${ }^{\text {"12 }}$.

Osim što se postponirani (sročni) atribut nalazi u frazemima, kao u primjerima:

[...] da su srodne duše rijetkost na kugli zemaljskoj. (KSM: 31); [...] najsretniji i najnesretniji čovjek na kugli zemaljskoj. (KSM: 53); Uplaši se da to nije prst božji. (KSM: 53); Ja sam, čovječe božji, samo izvršavao vašu zajedničku želju... (KI: 102)

${ }_{11}$ Usp. isto, str. 264.

$12 \quad$ K. BAGić, $n$. dj., str. 156. 
narušavanje neobilježenoga reda riječi uočava se i u ostalim imeničkim konstrukcijama:

Vratit će se, po bogzna koji put, mehaničan kao mrav, slijep, kratkovidan, opsjednut, stroj božji... (KI: 105); [...] ali da je to zakon božji... (KSM: 17); [...] sve bi štimalo, bio bi raj zemaljski, ne. (KSM: 28); Kad je otišla s dječicom u moru plavom da namače svoje bijele batake... (KSM: 33); [...] kao da je sam princ nebeski. (KSM: 84); Kurva stara, tako je on planirao i već je mene, svog najboljeg $i$ najvjernijeg kolegu, škartirao! (KSM: 138)

[...] običaja radi djevojke su stale priređivati sendviče iz zajedničkog materijala - šunkerice, vratine, pa baš prave šunke, tvrdo kuhanih jaja, faširanaca i paradajza. (BPH: 40); [...] ili je poslat po zadatku pa nije u odnosu s okolinom, tj. rodom ljudskim, već je odgovoran ekstraterestrijalnom centru. (BPH: 83)

kao i kod anteponiranoga nesročnog atributa:

Ni sudnjeg dana trumbenta ne bi ih razdrmala. (KSM: 130)

Simultanosti našega buđenja i ustajanja zacijelo je pridonijelo i to što je Slavko u neka doba grgljajući počeo iz svega glasa pjevati "O sole mio"kao stare slave belkantist. (BPH: 62-63)

te smještanja glagola na kraj rečenice:

Jesam sirotinja, ali toliko para opet imam. (KI: 64); Obična fuksa nije, to se odmah lijepo vidi. (KSM: 10o); [...] hoću u kino a kinte nemam. (KSM: 45); Možda bi fakin fakinski znao sačuvati njihovu tajnu, a možda bi i do ženidbe došlo. (KSM: 68)

\subsection{Ponavljanje}

Uz navedene postupke ekspresivne sintakse treba spomenuti i ponavljanja ${ }^{13}$ na sintaktičkoj i suprasintaktičkoj razini. Kada se govori o ponavljanju jezičnoga materijala, $u$ dosadašnjim se lingvostilističkim

${ }^{13}$ Usp. Ivan Marković, „Repeticija i reduplikacija u hrvatskome“, Suvremena lingvistika, Zagreb, god. LXIV. (2007.) br. 2., str. 141. - 157. 
istraživanjima uglavnom govorilo o reduplikaciji kao sintaktostilemu, ${ }^{14}$ međutim, u novijoj lingvističkoj literaturi razlikuju se dvije pojave: repeticija i reduplikacija.

Pod repeticijom se razumijeva ponavljanje jezičnih jedinica veličine riječi ili većih, kojim ponavljanjem nastaje jezična jedinica veća od riječi; stoga je repeticija ponajprije sintaktička pojava. Pod reduplikacijom se razumijeva sustavno ponavljanje fonoloških, fonetskih i morfoloških jedinica (fonema, slogova, afikasa, dijelova osnove ili osnove u cijelosti), kojim ponavljanjem nastaje nova jezična jedinica veličine riječi; stoga je reduplikacija ponajprije morfološka - fleksijska ili derivacijska - pojava. Moglo bi se reći da je reduplikacija poseban slučaj općenitijega pojma repeticije, no reduplikacija pokazuje još nekoliko važnih značenjskih i obličnih posebnosti koje ju bitno razlikuju od puke repeticije. ${ }^{15}$

U izdvojenim se primjerima uočavaju anaforička ponavljanja uklopljena u sintaktičke paralelizme. Anaforička ponavljanja u prozi nisu rijetkost. Zauzimajući jaku poziciju teksta (početak rečenice), anafora zaokuplja pozornost primatelja te čitavomu iskazu priskrbljuje ritmičnost i harmoničnost, ${ }^{16}$ npr.:

On je, mislim, morao tako. On možda nije imao drugog sebe osim u drugima. On možda nije imao druge sreće osim nesreće. (KI: 9)

Činilo se da je sama zemlja razotkrila pred nama bijela brda svoga tijela $i$ dopustila nam da po njima bauljamo i vršljamo poput neznatnih ali plodonosnih kukaca. Činilo se da ima toliko nevinog tla na koje prije nas nije stupila ljudska noga. Činilo se da smo upravo mi pozvani da nakon razaranja nastavimo život, preuzmemo nasljeđe, okrunimo vjekove uspješnom sintezom, da ih dovršimo. (KI: 11)

Uhvatili su ga na štos, čestita im! Čestita prefriganom gosponu Milčeku. To je tako kad luđaci slobodno šé́u ulicama našega lepega belega Zagreba i vuku te za rukav da piješ s njima. A kaj drugo možeš nego pristati jer si dekintiran, jer je to tak, da ludaci ne znaju kam će s lovom. Čestita Kurbli koji ga je upoznao s ovakvom nulom kao što je Geza! Čestita bolničaru koji ga je ščapio na vrijeme! Čestita ovom doktoru koji melje ko da

14 Usp. Krunoslav Pranjić, Jezik $i$ književno djelo. Ogledi za lingvostilističku analizu književnih tekstova, Školska knjiga, Zagreb, 1968., str. 123.

$15 \quad$ Isto, str. 141.

16 Usp. K. BAGIĆ, $n$. dj., str. 35 . 
je navijen! Čestita ovom vekteru koji ga moli da se ustane i pođe s njim do zajedničke sobe gdje ćore pravednici kao što je Glista. Čestita cijelom svijetu koji je konačno uspio da ga mrtvački zariba i smjesti u Stenjevec! (KSM: 157)

Ima neki bog u tome ako jednu noć provedeš s ludacima, pravim, koji imaju potvrdu od doktora da ne zabušavaju, da nisu švindleri, i koje treba poštovati jer je malo toga pravog $i$ neprefarbanog na tom svijetu ostalo. Nije lako biti luđak, dok su budali potrebne teške škole. Ima neki bog u tome ako te registrirani ludaci prime u svoje društvo i dopuste da slušaš njihove razgovore. (KSM: 159)

Postupci ponavljanja vide se i u parataktičkim konstrukcijama:

Moglo se ušutjeti i otploviti, moglo se odjednom govoriti, a mogli smo razgovarati i dvoje po dvoje. (BPH: 12)

Moglo se pričati, moglo se razmišljati. (BPH: 40)

Samo mene bode trnje po licu, samo mene žuljaju cipele. (KI: 74)

\section{Ponavljanja se javljaju i u ostalim pozicijama:}

Jasnije mi je sada, dok ovo pričam, da se on bacao tako bezobzirno i nepromišljeno $\boldsymbol{u}$ svaku akciju, $\boldsymbol{u}$ svaku opasnost, $\boldsymbol{u}$ novo i nepoznato, već zato što je osjećao da za njega nema opasnosti. (KI: 8)

Svakako, nije bio sam jer su ga ljudi uvijek okruživali, uvijek opterećivali svojim nevoljama, uvijek dopuštali da ih odvede labirintima svojih beskonačnih pothvata u nešto u što sami nikada ne bi ušli. (KI: 9)

Čini mi se još tamniji, još sporiji, još pognutiji nego inače. (KI: 78)

...pravim fakinom koji zna da nije svaki dan svetak, ali opet ni petak. Da smo jednom gornji a drugi put donji. Da nekog mi zaribamo, a neko nas. Da su ženske prefrigane, ali da je to zakon božji... (KSM: 17)

Počeo si utvarati da je sinek kakvog lovaroša obrtnika, da se fura u rekordu i da mačke od miline samo zavijaju kad ih forfara. (KSM: 32)

Kako mu je u vojsci bilo gala jer je kopao u domu armije, kako je svake subote imao frišku žensku, kako je živio ko lord od tringelta i kako još ni dan-danas ne zna rastaviti karabin. (KSM: 42)

Kao, ona je pod njim ćorila. Kao, tri dana nije oka sklopila. Kao, treba je pustiti na miru. (KSM: 114)

A znao sam što treba da učinim. Činilo mi se da znam, da samo treba da pričekam da odluka isplovi iz dubine. (BPH: 5) 
Kod Šoljana se uočava učestalo anaforičko ponavljanje priloga mož$d a$ čime se sugerira neizvjesnost :

Možda je osjećao da je svaka akcija koju poduzme za njega samog bez ikakvih posljedica, i možda je zapravo tražio, nervozno i histerično tražio takvu akciju koja će posljedice imati. A možda je njega, koji je bio lud, slijep, nespretan, djetinjast, slab (sve to u većoj mjeri nego mi ostali) štitila njegova zvijezda. (KI: 8)

Možda ih je samo on znao tako izgovoriti da u njima oživi skriveni smisao. Možda je jedini on mogao pokazati kako ima smisla da se čini upravo ono što činimo mi. Ili da se uopće što čini. Možda je taj smisleni život davala riječima njegova neukrotiva energija, intenzivna žed za akcijom, a možda stvarno ima ljudi kojima se otkriva skriveni smisao stvari, koji je drugima nedokučiv. Možda je Roko bio jedan od tih ljudi. Možda je u nekom drugom vremenu mogao biti kakav prorok. Što je uostalom ovakav kakav jest $i$ mogao biti u ovom vremenu? (KI: 20)

Možda sam zaviknuo od radosti. Možda sam zapjevao kakvu od rodoljubnih, pobjedničkih pjesama koje su i moji preci pjevali, nešto kao Prosto zrakom ptica leti ili Na vojsku, na vojsku, vitezi izbrani, ili sam možda samo vikao „Za mnom, za mnom" ili „Naprijed", ili sam naprosto urlao kao vuk... [...] Iza mene je još uvijek grmjela jeka iz tunela: možda je moj glas zaostao iza mene da živi tamo svojim posebnim podzemnim životom, a možda su se to zaista glasali preci. (KI: 111)

Možda nikada i nije bilo drugog svijeta, rekao sam samome sebi, kao da se opravdavam. Možda sam u ovoj pustoši od početka, možda smo svi u njoj od početka, samo mi nije bilo dano da je vidim tako jasno kao sada. Možda se nikad nisam ni maknuo odavde. Možda nisam krenuo ni na kakav izlet. Možda je ovo zapravo blagovijest, spas. Možda je ovo ona konačna sloboda kojoj su preci toliko težili, i ja sam na cilju. (KI: 112)

Stilske figure na morfološkoj odnosno, ako govorimo o funkcijama vrsta i oblika riječi u sintaktičkim jedinicama i tekstu, na morfosintaktičkoj razini nastaju postupkom imutacije (zamjene) i uglavnom se temelje na gramatičkoj sinonimiji, tj. „konkurenciji gramatičkih oblika odnosno na uporabi jednoga gramatičkog oblika u funkcijama i/ili značenjima koji su tipični za drugi ${ }^{{ }{ }^{17}}$. Za stilistiku je posebno zanimljiva kontekstualna sinonimija "kod koje se uspostavlja bliskost osnovnoga

$17 \quad$ I. Pranjković, $n$. dj., str. 23. 
značenje neke forme sa sekundarnim, perifernim značenjem druge forme iste kategorije ${ }^{{ }^{18} 8}$. Pri tome treba imati u vidu cijeli sinonimski niz jer se oblici mogu razlikovati u semantičkim i/ili stilskim nijansama na način da je je jedna neutralna, a druge obilježene. Zajednički naziv za različite vrste gramatičke sinonimije jest enalaga. U hrvatskome se jeziku najčešće pojavljuju enalaga lica, broja, vremena, načina i roda.

Enalaga lica ostvaruje se, primjerice, upotrebom pripovjedačkoga ili historijskoga imperativa koji se upotrebljava u živu pripovijedanju prošlih događaja. Takav imperativ koji nalazimo kod Majdaka izrazito je stilski obilježen:

Fino smo ja i Glista to izvodili. Bili smo šegrti. Tko nam je što mogao? Uveče vremena za izvoz. Radi što te volja. Idi u kino na kaubojski filmić, idi nedjeljom na tekmu, zezaj se u slastičarnici ili ispred kućice u kojoj stari Jumbi peče kostanje, švercaj se na treski, štosa radi, pronjuši po tř̌nici; drpi koju breskvu ili narandžu, ščipni za guz koju kumicu, visi u bircuzu ili mlječnjaku gdje frajerice i frizerke piju kavice, pogledaj koga ima na tramvajskoj stanici, tko igra rukoš ili nogoš na školskom igralištu, nasloni se na Namu i čekaj dok kiša prestane, kuži dobre pičke, pokušaj se ubaciti kod koje naivke, popuši jednu, dve pljuge u društvu kakvog platfusiste, do mile volje zijevaj i prostači - Isuse, možeš li zamisliti nešto više perfa?! (KSM: 6-7)

Osim historijskoga imperativa potvrđen je i svevremenski imperativ koji je također stilogen:

Ali soliti pamet nekome tko misli da je posrkao sve znanje! Savjetuj ga prijateljski, on će odnekud zvleći sumnju da radiš za sebe i da ga namjeravaš zgurati. (KSM: 29)

${ }_{18}$ M. KATNIĆ-BAKARŠIĆ, $n . d j$., str. 245. 


\subsection{Epitet}

Epitet se najčešće definira kao pridjev koji pobliže određuje imenicu s ciljem da se naglasi kakvo svojstvo ili da izraz bude slikovitiji, međutim epitet u širem smislu može biti bilo koja riječ koja karakterizira. ${ }^{19}$

Antica Antoš smatra da je vrlo teško pronaći izražajan i funkcionalan epitet te da se odabirom određenoga epiteta pokazuju autorov kriterij i ukus. To potvrđuje navodeći Voltairevu misao: „Iako se pridjev s imenicom slaže u rodu, broju i padežu, on joj je katkad najveći neprijatelj. ${ }^{{ }_{20}} \mathrm{O}$ tome slično misli i Antun Barac:

Pridjev može biti potreban, ali je često znak težnje za opsežnosti i šarenilom. Potreban je onda kad je nužan za razumijevanje onoga što se kaže imenicom ili kad joj pruža potrebnu značajku. No u nevješta stilista znači atribut često samo nepotrebno razbacivanje bojama ili prikrivanje pravih kontura predmeta... Upotreba pridjeva značajka je mladosti kad čovjek sve pojave gleda manje-više u bojama. ${ }^{21}$

Unatoč uvriježenu mišljenju da epitetu nije mjesto u proznome izrazu, nerijetko ga nalazimo u novelama i romanima. To potvrđuju sljedeći primjeri:

Je li u njegovoj urođenoj nervozi bilo nekoga magnetskog šarma, zamamnog obećanja... (KI: 6)

[...] da bih mogao objasniti onu nervoznu vitalnost, neizlječivi nemir, neodoljivi poriv za akcijom, neutaživu žed za promjenom... (KI: 6)

\section{Zaključak}

Slamnigov i Šoljanov rad često se dovodi u vezu s autorima koje su prevodili pa je njihova proza često uspoređivana s angloameričkom tvrdokuhanom prozom (engl. hard-boiled prose), osobito Slamnigova s Hemingwayevom zbog oponašanja svakodnevnoga govora i govorne

19 Usp. K. BAgić, $n$. $d j$., str. 112.

${ }_{20}$ Antica Antoš, Osnove lingvističke stilistike, Školska knjiga, Zagreb, 1974., str. 69.

21 Isto. 
sintakse, zatim uporabe tzv. „ligamentnih“ čestica (to jest, odnosno) kao i različitih oblika ponavljanja. To je obilježje svoje proze opisao i sam Slamnig:

Ja sam svakako počeo s tim da pišem prozu koja zvuči kao razgovor, ne znam da li sam jednu napisao u trećem licu, sve su u prvom licu, sve imaju ton ćakule, pričanja (...) Dakle, ja jesam išao za tim da pišem kao što se govori, do te mjere da gotovo da se osjeti zamuckivanje u prozi, ili da često puta ponovim "to jest“, da sâm svoju rečenicu idem tumačiti, kao da me sad ovaj nije dobro razumio, kao da mi je živi slušalac prisutan. ${ }^{22}$

Proza u trapericama od samoga se početka udaljila od „akademske ozbiljnosti“ književnih djela stilske formacije koja joj je prethodila. Postupcima ekspresivne sintakse ostvarena je stilizacija spontanoga usmenog pripovijedanja kojom se nastojalo suprotstaviti modelima proze sa sveznajućim pripovjedačem, realističkomu romanu 19. stoljeća i romanu sa „socijalno-pedagoškom društvenom funkcijom“ te vratiti se vjerodostojnosti pripovijedanja ovaj put novoga sadržaja i izvan zadanih kalupa.

\section{Literatura}

- Antoš, Antica, Osnove lingvističke stilistike, Školska knjiga, Zagreb, 1974.

- Bagić, Krešımir, Rječnik stilskih figura, Školska knjiga, Zagreb, 2012.

- Flaker, Aleksandar, Proza u trapericama, Sveučilišna naklada Liber, Zagreb, 1983.

- HoDžıĆ, JASMIN, „O nekim načelima sintaksičke analize književnoumjetničkog teksta“, Književni jezik, Institut za jezik Univerziteta u Sarajevu, Sarajevo, br. 27., (2016.), str. 189. - 203.

${ }_{22}$ Željko Ivanjek, „Ponekad ponedjeljkom: Razgovor s Ivanom Slamnigom“, Stilistika, <https://stilistika.org/pisci-i-stilovi/ivan-slamnig/53-ponekad-ponedjeljkom>, (17. XI. 2018.). 
- Ivan Marković, „Repeticija i reduplikacija u hrvatskome“, Suvremena lingvistika, Zagreb, god. LXIV. (2007.) br. 2., str. 141. - 157.

- Ivanjek, Željko, „Ponekad ponedjeljkom: Razgovor s Ivanom Slamnigom", Stilistika, <https://stilistika.org/pisci-i-stilovi/ ivan-slamnig/53-ponekad-ponedjeljkom>, (17. XI. 2018.).

- Katnić-BaKaršić, Marina, Stilistika, Ljiljan, Sarajevo, 2001.

- Majdak, Zvonimir, Kužiš, stari moj, Znanje, Zagreb, 2001.

- Pranjić, Krunoslav, Jezik i književno djelo. Ogledi za lingvostilističku analizu književnih tekstova, Školska knjiga, Zagreb, 1968.

- Pranjković, Ivo, „Stilske figure i gramatika“, Jezik književnosti $i$ književni ideologemi: zbornik radova 35. seminara Zagrebačke slavističke škole, BAGIĆ, KREŠIMIR (ur.), Zagrebačka slavistička škola, Zagreb, 2007., str. 21. - 25.

- PURIŠ, BernisA, „Ekspresivna sintaksa u književnoumjetničkom tekstu (na primjeru Grozdanina kikota Hamze Hume)“, Post scriptum, Bihać, br. 1., (2010. - 2011.), str. 24. - 30.

- Simeon, Rikard, Enciklopedijski rječnik lingvističkih naziva, Matica hrvatska, Zagreb, 1969.

- Slamnig, Ivan, Bolja polovica hrabrosti, Večernji list, Zagreb, 2004.

- Šoljan, Antun, Kratki izlet, Večernji list, Zagreb, 2004. 
Original scientific paper

Received on September 28, 2019

IVONA BAKOVIĆ

University of Mostar, Faculty of Humanities and Social Sciences

\section{SYNTACTIC STYLE INTENSIFIERS IN THE CROATIAN JEANS-PROSE NOVELS}

\section{Abstract}

The paper analyzes syntactic style intensifiers in three Croatian jeans-prose novels: Kratki izlet by Antun Soljan, Kuzis, stari moj by Zvonimir Majdak and Bolja polovica hrabrosti by Ivan Slamnig. It covers phenomena and procedures at the syntactic level (decomposed predicate, ellipsis, reticention, nominative sentences, parceling, inversion, repetitions and epithets) in which we find discrepancies from the usual sentence structure. Since jeans-prose is concerned with stylization of spoken language, procedures such as ellipsis and reticention are used to make impression of spontaneity and unpreparedness, while repetitions can reveal emotional state of protagonists besides contributing to easiness and relaxation.

Keywords: jeans prose; expressive syntax; syntactic style intensifier; figures of speech; sentence 